\title{
KAJIAN TENTANG MODEL BANGKITAN PERGERAKAN PERMUKIMAN KAWASAN CIWASTRA KOTA BANDUNG
}

\author{
Hana Karimah dan Juang Akbardin \\ Program Studi Teknik Sipil Universitas Pendidikan Indonesia, INDONESIA \\ E-mail: $\underline{\text { hanakrmh@gmail.com, akbardien@upi.edu }}$
}

\begin{abstract}
ABSTRAK
Meningkatnya jumlah penduduk Kota Bandung menyebabkan peningkatan kebutuhan tempat tinggal. Untuk memenuhinya, dibangun permukiman baru di wilayah Bandung Timur termasuk Ciwastra. Adanya permukiman baru akan menimbulkan peningkatan volume lalu lintas, apabila peningkatan volume lalu lintas tidak berimbang dengan peningkatan kapasitas jalan, maka akan terjadi permasalahan transportasi. Tujuan penelitian ini adalah untuk memodelkan bangkitan pergerakan yang dihasilkan permukiman. Data yang dibutuhkan yaitu data sosio ekonomi warga yang didapat dengan cara penyebaran angket/kuisioner, selanjutnya diolah untuk menghasilkan model bangkitan pergerakan dengan metode analisis regresi berganda. Hasil penelitian yaitu, model bangkitan pergerakan Perumahan de Green Grande adalah Y1=6,068+1,239 X4 +1,435 X5 + 0,855 X7+1,166 X8, Jingga Residence Y2 = $2,554+1,143$ X3 + 1,041 X4 + 1,011 X5 +1,256 X6 + 1,2045 X7, Pesona Ciwastra Permai Y3 = 7,540 $+2,874$ X5 + 1,696 X6 + 0,552 X8, dan Buana Ciwastra Y4 = 5,840 + 1,143 X3 + 2,108 X5 + 1,3295 X6. X3 adalah pekerjaan, X4 pendapatan, X5 jumlah anggota keluarga, X6 jumlah anggota keluarga yang bekerja, X7 jumlah perjalanan per hari, X8 jumlah kepemilikan motor.
\end{abstract}

Kata kunci: bangkitan pergerakan; model bangkitan pergerakan; permukiman.

\begin{abstract}
The increase of Bandung population is increase demands of housing. To cover it, East Bandung become residential area, included Ciwastra. New housing will increase traffic volume, if it's not followed by the increase of road capacity, there will be transportation problem. The main purpose of this research is to model housing trip generation. The required data is citizen socio-economic, that obtained by spreading questionnaires and then further processed to get trip generation models with multiple regression analysis. The results are, trip generation model of de Green Grande Residence is $Y 1=6,068+1,239 X 4$ $+1,435 X 5+0,855 X 7+1,166 X 8$, Jingga Residence is $Y 2=2,554+1,143 X 3+1,041 X 4+1,011 X 5$ $+1,256$ X6 + 1,2045 X7, Pesona Ciwastra Permai is Y3 = 7,540+2,874 X5 + 1,696 X6 + 0,552 X8, dan Buana Ciwastra is $Y 4=5,840+1,143$ X3 + 2,108 X5 + 1,3295 X6. X3 is occupation, X4 is income, X5 is amount of family member, X6 is amount of worker in family member, X7 is amount of trip in a day, X8 is amount of motorcycle ownership.
\end{abstract}

Keywords: trip generation; trip generation model; housing.

\section{PENDAHULUAN}

Jumlah penduduk Kota Bandung terus meningkat sehingga kebutuhan tempat tinggal juga meningkat. Untuk memenuhi kebutuhan tempat tinggal, dibangun permukiman baru di wilayah Bandung Timur. Salah satu daerah yang menjadi kawasan permukiman adalah Ciwastra. Dengan dibangunnya permukiman baru akan menimbulkan dampak pada berbagai aspek, seperti lingkungan, kesehatan, sosial, dan ekonomi. Selain itu, pembangunan permukiman juga tentunya akan meningkatkan pergerakan pada wilayah sekitar, karena adanya bangkitan pergerakan yang dihasilkan dari permukiman. Hal tersebut menyebabkan peningkatkan volume lalu lintas, khususnya pada jam sibuk pagi dan sore. Namun, tidak berimbangnya volume lalu lintas dan kapasitas pada ruas Jalan Ciwastra menyebabkan permasalahan transportasi yang lebih lanjut.

\section{Tujuan Penelitian}

Tujuan penelitian ini adalah untuk mengetahui model bangkitan pergerakan dari permukiman yang menjadi objek penelitian. Secara spesifik tujuan penelitian adalah

1. Mengetahui hubungan variabel yang pembentuk model bangkitan pergerakan

2. Menganalisis karakteristik perilaku pembentuk bangkitan pergerakan pemukiman

3. Merumuskan model bangkitan pergerakan sesuai dengan karakteristik penghuni pemukiman 


\section{Interaksi Tata Guna Lahan dan Transportasi}

Setiap tata guna lahan atau setiap ruang kegiatan mempunyai jenis kegiatan tertentu (terdiri atas kegiatan sosial, ekonomi, kebudayaan, dan lain-lain) yang akan membangkitkan pergerakan dan akan menarik pergerakan dalam proses pemenuhan kebutuhan, intensitasnya tergantung pada jenis tata guna lahannya. Adanya perkembangan ekonomi, sosial, dan politik akan mempengaruhi besarnya volume lalu lintas (Morlok. 1991). Jumlah dan jenis lalu lintas yang dihasilkan oleh setiap tata guna lahan merupakan hasil dari parameter sosial dan ekonomi (Black. 1981). Tata guna lahan adalah salah satu faktor utama yang menentukan pergerakan dan aktivitas (Khisty dan Lall. 2003). Jika terdapat pembangunan dan pengembangan kawasan baru seperti pusat perbelanjaan, superblok, dan lain-lain, tentu akan timbul tambahan bangkitan dan tarikan lalulintas baru akibat kegiatan tambahan di dalam dan sekitar kawasan tersebut, dan itu akan memberikan pengaruh langsung terhadap sistem jaringan jalan di sekitarnya (Tamin. 2000). Karena itulah, setiap kali terjadi perkembangan tata guna lahan harus diikuti dengan kegiatan untuk melakukan perkiraan, estimasi, dan prediksi jumlah arus perjalanan antara lokasi asaltujuan melalui analisis dengan melibatkan semua variabel yang saling terkait satu sama lain baik yang terkait dengan tata guna lahan seperti variabel jumlah penduduk, pendapatan masyarakat, pembangunan gedung maupun yang tekait dengan sistem transportasi seperti pembukaan jalan baru, pembangunan terminal dan sebagainya dengan metodologi yang sesuai (Miro. 2011). Juga kecepatan kendaraan tergantung dari ruas jalan dan hambatan samping yang melewati suatu kawasan (Syaiful dan Lutfi Akbar, 2015; Syaiful, 2015).

\section{Perencanaan Transportasi}

Dalam sistem perencanaan transportasi terdapat empat langkah yang saling terkait satu dengan yang lain (Tamin. 1997), yaitu:

1. Bangkitan pergerakan (Trip generation)

2. Distribusi perjalanan (Trip distribution)

3. Pemilihan moda (Modal split)

4. Pembebanan jaringan (Trip assignment)

\section{Bangkitan Pergerakan}

Bangkitan pergerakan dapat diartikan sebagai banyaknya jumlah perjalanan/ pergerakan/lalu lintas yang dibangkitkan oleh suatu zona (kawasan) per satuan waktu (per detik, menit, jam, hari, minggu, dan seterusnya) (Miro. 2005). Faktor-faktor yang mempengaruhi bangkitan pergerakan menurut Tamin (2000), antara lain :

1. Bangkitan Pergerakan untuk Manusia

2. Pendapatan

3. Pemilikan kendaraan

4. Kepadatan daerah permukiman

5. Tarikan Pergerakan untuk Manusia

6. Bangkitan dan tarikan pergerakan untuk barang

Pemodelan bangkitan pergerakan menggunakan analisis regresi berganda. Hal ini sangat diperlukan dalam realita yang menunjukkan bahwa beberapa peubah tata guna lahan secara simultan ternyata mempengaruhi bangkitan pergerakan (Tamin. 2000).

\section{METODE PENELITIAN}

Penelitian ini akan dilakukan pada ruas Jalan Ciwastra, Kota Bandung, Provinsi Jawa Barat. Responden penelitian adalah sampel warga dari permukiman pada ruas Jalan Ciwastra, yaitu: Perumahan de Green Grande, Jingga Residence, Pesona Ciwastra Permai, dan Buana Ciwastra.

Metode penelitian yang digunakan adalah metode kuantitatif. Berdasarkan kealamiahan tempat penelitian menggunakan metode survei yang artinya data didapat dari tempat tertentu yang alamiah (bukan buatan), tetapi peneliti melakukan perlakuan dalam pengumpulan data, misalnya dengan mengedarkan kuisioner, tes, dan sebagainya (Sugiyono. 2011). Langkah-langkah penelitian dijelaskan pada Diagram Alir Penelitian berikut: 


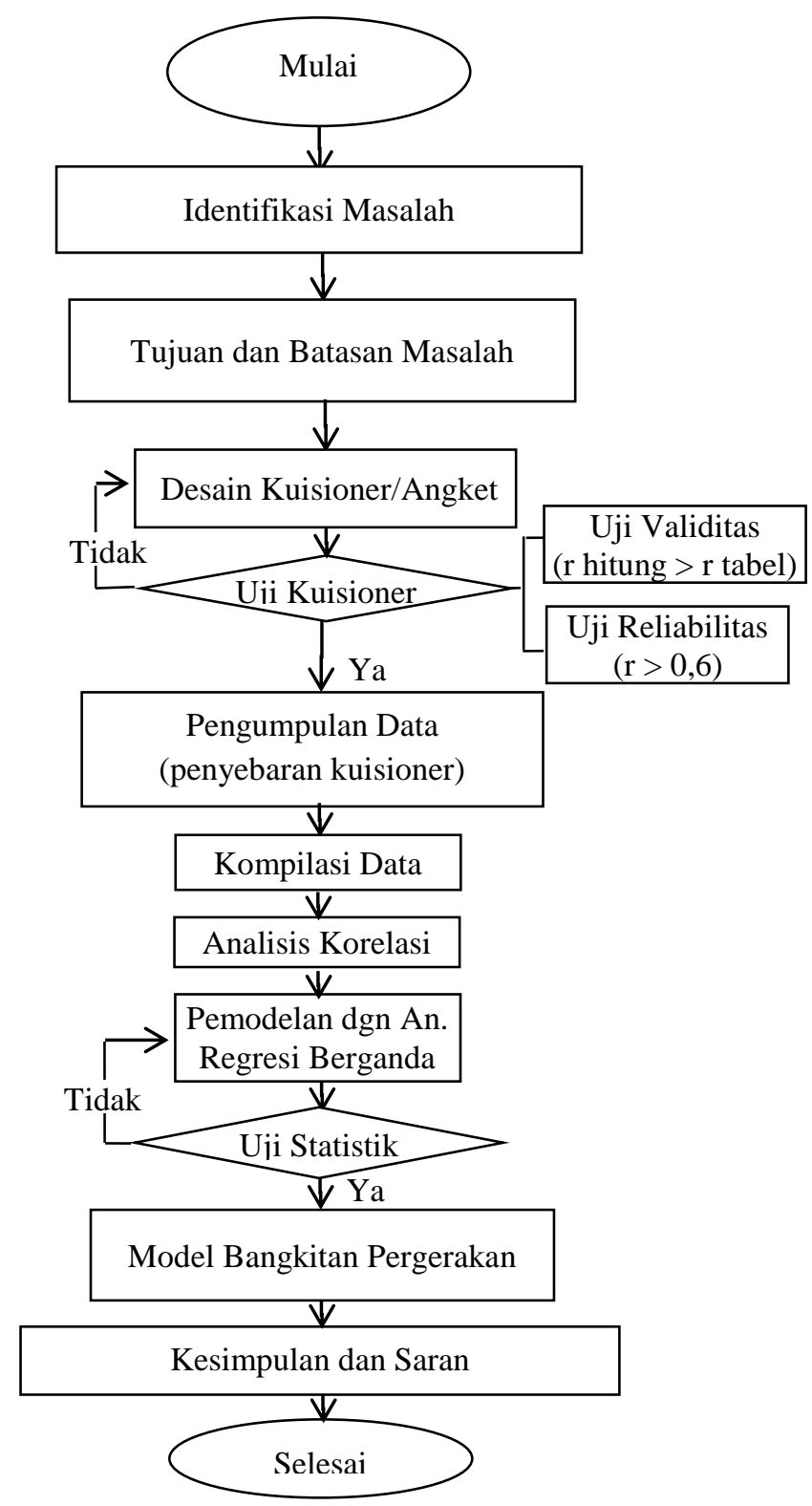

Gambar 2 Diagram Alir Penelitian

\section{Desain dan Uji Kuisioner}

Mengacu pada teori yang dikemukakan Black (1981) bahwa bangkitan adalah hasil dari parameter sosial ekonomi, maka dibuat angket/kuisioner yang diuji coba pada 30 sampel untuk menguji validitas dan reliabilitasnya. Hasil uji coba tersebut menunjukan bahwa variabel yang mempengaruhi bangkitan pada permukiman-permukiman yang menjadi objek penelitian adalah: pekerjaan, pendapatan keluarga per bulan (rupiah), jumlah anggota keluarga (orang), jumlah anggota keluarga yang bekerja (orang), jumlah perjalanan yang dilakukan anggota keluarga per hari, jumlah kepemilikan sepeda motor (unit), dan jumlah kepemilikan mobil (unit). Angket/kuisioner yang sudah teruji validitas dan reliabilitas selanjutnya akan disebar ke beberapa sampel warga permukiman dengan teknik sampling sebagai berikut :

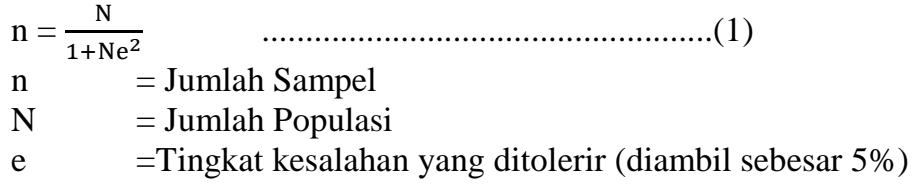$$
\mathrm{n} \quad=\text { Jumlah Sampel }
$$$$
\mathrm{N} \quad=\text { Jumlah Populasi }
$$$$
\text { e } \quad=\text { Tingkat kesalahan yang ditolerir (diambil sebesar } 5 \% \text { ) }
$$ 


$$
\begin{aligned}
& \text { Analisis Korelasi } \\
& \mathrm{r}=\frac{\mathrm{N} \sum_{\mathrm{i}=1}^{\mathrm{N}}\left(\mathrm{X}_{\mathrm{i}} \mathrm{Y}_{\mathrm{i}}\right)-\sum_{\mathrm{i}=1}^{\mathrm{N}}\left(\mathrm{X}_{\mathrm{i}}\right) \cdot \sum_{\mathrm{i}=1}^{\mathrm{N}}\left(\mathrm{Y}_{\mathrm{i}}\right)}{\sqrt{\left[\sum_{\mathrm{i}=1}^{\mathrm{N}}\left(\mathrm{X}_{\mathrm{i}}\right)^{2}-\left(\sum_{\mathrm{i}=1}^{\mathrm{N}}\left(\mathrm{X}_{\mathrm{i}}\right)\right)^{2}\right] \cdot\left[\sum_{\mathrm{i}=1}^{\mathrm{N}}\left(\mathrm{Y}_{\mathrm{i}}\right)^{2}-\left(\sum_{\mathrm{i}=1}^{\mathrm{N}}\left(\mathrm{Y}_{\mathrm{i}}\right)\right)^{2}\right]}}
\end{aligned}
$$

\section{Analisis Regresi Berganda}

$\mathrm{Y}=\mathrm{b}_{0}+\mathrm{b}_{1} \mathrm{X}_{1}+\mathrm{b}_{2} \mathrm{X}_{2}+\ldots+\mathrm{b}_{\mathrm{z}} \mathrm{X}_{\mathrm{z}}$

Untuk mendapatkan $b_{0}$ dan $b_{1}-b_{z}$ didapat dengan menyelesaikan persamaan berikut (Tamin. 2003).

$\mathrm{Nb}_{0}+\mathrm{b}_{1} \sum_{\mathrm{i}=1}^{\mathrm{N}} \mathrm{X}_{1 \mathrm{i}}+\mathrm{b}_{2} \sum_{\mathrm{i}=1}^{\mathrm{N}} \mathrm{X}_{2 \mathrm{i}}+\mathrm{b}_{3} \sum_{\mathrm{i}=1}^{\mathrm{N}} \mathrm{X}_{3 \mathrm{i}}$

$=\sum_{\mathrm{i}=1}^{\mathrm{N}} \mathrm{Yi}$

$\mathrm{b}_{0} \sum_{\mathrm{i}=1}^{\mathrm{N}} \mathrm{X}_{1 \mathrm{i}}+\mathrm{b}_{1} \sum_{\mathrm{i}=1}^{\mathrm{N}}\left(\mathrm{X}_{1 \mathrm{i}}\right)^{2}+\mathrm{b}_{2} \sum_{\mathrm{i}=1}^{\mathrm{N}}\left(\mathrm{X}_{1 \mathrm{i}} \cdot \mathrm{X}_{2 \mathrm{i}}\right)$

$+\mathrm{b}_{3} \sum_{\mathrm{i}=1}^{\mathrm{N}}\left(\mathrm{X}_{1 \mathrm{i}} \cdot \mathrm{X}_{3 \mathrm{i}}\right)=\sum_{\mathrm{i}=1}^{\mathrm{N}}\left(\mathrm{X}_{1 \mathrm{i}} . \mathrm{Yi}\right)$

$\mathrm{b}_{0} \sum_{\mathrm{i}=1}^{\mathrm{N}} \mathrm{X}_{2 \mathrm{i}}+\mathrm{b} 1 \sum_{\mathrm{i}=1}^{\mathrm{N}}\left(\mathrm{X}_{1 \mathrm{i}} \cdot \mathrm{X}_{2 \mathrm{i}}\right)+\mathrm{b} 2 \sum_{\mathrm{i}=1}^{\mathrm{N}}\left(\mathrm{X}_{2 \mathrm{i}}\right)^{2}$

$+\mathrm{b} 3 \sum_{\mathrm{i}=1}^{\mathrm{N}}\left(\mathrm{X}_{2 \mathrm{i}} \cdot \mathrm{X}_{3 \mathrm{i}}\right)=\sum_{\mathrm{i}=1}^{\mathrm{N}}\left(\mathrm{X}_{2 \mathrm{i}} \cdot \mathrm{Yi}\right)$

$\mathrm{b}_{0} \sum_{\mathrm{i}=1}^{\mathrm{N}} \mathrm{X}_{3 \mathrm{i}}+\mathrm{b}_{1} \sum_{\mathrm{i}=1}^{\mathrm{N}}\left(\mathrm{X}_{1 \mathrm{i}} \cdot \mathrm{X}_{3 \mathrm{i}}\right)+\mathrm{b}_{2} \sum_{\mathrm{i}=1}^{\mathrm{N}}\left(\mathrm{X}_{2 \mathrm{i}} \cdot \mathrm{X}_{3 \mathrm{i}}\right)$

$+\mathrm{b}_{3} \sum_{\mathrm{i}=1}^{\mathrm{N}}\left(\mathrm{X}_{3 \mathrm{i}}\right)^{2}=\sum_{\mathrm{i}=1}^{\mathrm{N}}\left(\mathrm{X}_{3 \mathrm{i}}\right.$. Yi $)$

Uji Statistik

1. Uji Determinasi

$R^{2}=\frac{\overline{b_{1} \sum x_{1 i} y_{i}+b_{2} \sum x_{2 i}} y_{i}+b_{3} \sum x_{3 i} y_{i}+b_{z} \sum x_{z i} y_{i}}{\sum y_{i}^{2}}$

2. $\quad$ Uji F (Uji Signifikansi Simultan)

$\mathrm{F}=\frac{R^{2} /(K)}{\left(1-R^{2}\right) /(N-K-1)}$

$\mathrm{N}=$ Jumlah sampel

$\mathrm{K}=$ jumlah variabel bebas yang digunakan (Sugiyono. 2011).

3. Uji t (Uji Signifikansi Parsial)

$\mathrm{t}=\frac{\mathrm{b}_{\mathrm{k}}-\beta_{\mathrm{k}}}{\mathrm{Sb}_{\mathrm{k}}}$

$\mathrm{k}=$ variabel bebas

$\beta=$ koefisien regresi $=$ dianggap 0

$\mathrm{b} \quad=$ konstanta regresi

$\mathrm{Sb}=$ simpangan baku kekeliruan (galat baku) (BPS. 2013)

\section{HASIL DAN PEMBAHASAN}

\section{Analisis Model Bangkitan Pergerakan}

Penentuan Variabel Bebas yang Terpilih dengan Uji Korelasi (r)

Data dari hasil kuisioner tidak seluruhnya dijadikan variabel bebas bangkitan, yang akan digunakan adalah yang memiliki korelasi tertinggi terhadap bangkitan, namun tidak memiliki korelasi tinggi terhadap sesama variabel bebas yang akan digunakan. Untuk menghitung koefisien korelasi menggunakan menggunakan rumus (2) berikut hasil perhitungan korelasi:

Tabel 1 Matriks Korelasi antara variabel pada Perumahan de Green Grande Residence

\begin{tabular}{|c|c|c|c|c|c|c|c|c|c|c|}
\hline No & \multicolumn{2}{|c|}{ Variabel } & Y1 & X3 & X4 & X5 & X6 & X7 & X8 & X9 \\
\hline 1 & Bangkitan & Y1 & 1 & & & & & & & \\
\hline 2 & Pekerjaan & X3 & 0.456 & 1 & & & & & & \\
\hline 3 & Pendapatan & X4 & 0.639 & 0.19 & 1 & & & & & \\
\hline 4 & Jml Ang.Keluarga & X5 & 0.696 & 0.31 & 0.21 & 1 & & & & \\
\hline 5 & Jml yg bekerja & X6 & 0.227 & -0.1 & 0.05 & 0.168 & 1 & & & \\
\hline 6 & Pergerakan/hr & X7 & 0.718 & 0.12 & 0.35 & 0.342 & -0.13 & 1 & & \\
\hline 7 & Jml Motor & X8 & 0.532 & 0.1 & 0.15 & 0.384 & 0.42 & 0.27 & 1 & \\
\hline 8 & Jml Mobil & X9 & 0.255 & 0.21 & 0.21 & 0.180 & -0.15 & 0.04 & -0.2 & 1 \\
\hline
\end{tabular}

Perhitungan Analisis Regresi Linier Berganda

Pemodelan bangkitan pergerakan menggunakan analisis regresi-linier berganda. Nilai $b_{0}$ dan $b_{1}-b_{z}$ bisa didapat dengan menyelesaikan beberapa persamaan linier (3a), maka didapat : 
$\mathrm{b}_{0}=6,068$

$$
\mathrm{b}_{3}=0,855
$$

$\mathrm{b}_{1}=1,239$

$\mathrm{b}_{4}=1,166$

$\mathrm{b}_{2}=1,435$

$\mathrm{Y} 1=6,068+1,239 \mathrm{X} 4+1,435 \mathrm{X} 5+0,855 \mathrm{X} 7+1,166 \mathrm{X} 8$

Uji Determinasi

Berikut hasil perhitungan nilai Koefisien Determinasi $\left(\mathrm{R}^{2}\right)$ menggunakan rumus (4):

$R^{2}=\frac{b_{1} \sum x_{4 i} y_{i}+b_{2} \sum x_{5 i} y_{i}+b_{3} \sum x_{7 i} y_{i}+b_{4} \sum x_{8 i} y_{i}}{\sum y_{i}^{2}}$

$\mathrm{R}^{2}=0,919$

Koefisien determinasi $\left(\mathrm{R}^{2}\right)$ sebesar 0,919 mendekati 1 atau 91,04\% mendekati $100 \%$.

Uji F (Uji Signifikansi Simultan)

Perhitungan nilai $\mathrm{F}$ menggunakan rumus (5) seperti berikut:

$F=\frac{R^{2} /(K)}{\left(1-R^{2}\right) /(N-K-1)}=\frac{0,919 /(4)}{(1-0,919) /(41-4-1)}$

$F h=102,67$

Untuk kesalahan $5 \%$, dk pembilang $=\mathrm{k}=4$, $\mathrm{dk}$ penyebut $=\mathrm{n}-\mathrm{k}-1=36, \mathrm{Ft}=2,642$. Dari hasil tersebut berarti $\mathrm{Fh}=10,67>\mathrm{Ft}=2,642$, maka dapat disimpulkan model regresi berganda tersebut dapat digunakan.

Uji t (Uji Signifikansi Parsial)

Perhitungan nilai $\mathrm{t}$ menggunakan rumus (6) seperti berikut:

$$
\mathrm{t}_{\mathrm{h} 1}=\frac{\mathrm{b}_{1}-\beta_{1}}{\mathrm{Sb}_{1}}=\frac{1,239}{0,16}=7,61 \mathrm{t}_{\mathrm{h} 2}=7,47 \quad \mathrm{t}_{\mathrm{h} 3}=7,31 \quad \mathrm{t}_{\mathrm{h} 4}=4,16
$$

Untuk kesalahan 5\% dan dk = n-k-1 = 36, maka t tabel = 1,645. Dari hasil perhitungan diketahui bahwa $\mathrm{t}$ hitung masing-masing variabel $>\mathrm{t}$ tabel $=1,645$, maka dapat disimpulkan masing-masing variabel bebas berpengaruh terhadap variabel terikat.

Tabel 2 Rekap Hasil Analisis Model Bangkitan Pergerakan pada masing-masing Perumahan

\begin{tabular}{|l|l|}
\hline \multicolumn{1}{|c|}{ Perumahan } & \multicolumn{1}{|c|}{ Model Bangkitan Pergerakan } \\
\hline De Green Grande & $\mathrm{Y} 1=6,068+1,239$ X4 +1,435 X5 + 0,855 X7+1,166 X8 \\
\hline Jingga Residence & $\begin{array}{l}\mathrm{Y} 2=2,554+1,143 \mathrm{X} 3+1,041 \mathrm{X} 4+1,011 \mathrm{X} 5+1,256 \text { X6 } \\
+1,2045 \mathrm{X} 7\end{array}$ \\
\hline $\begin{array}{l}\text { Pesona Ciwastra } \\
\text { Permai }\end{array}$ & $\mathrm{Y3}=7,540+2,874$ X5 + 1,696 X6 + 0,552 X8 \\
\hline Buana Ciwastra & $\mathrm{Y} 4=5,840+1,143 \mathrm{X} 3+2,108 \mathrm{X} 5+1,3295 \mathrm{X} 6$ \\
\hline \multicolumn{2}{|c|}{ JUMLAH } \\
\hline
\end{tabular}

Sumber : Hasil Analisis Data

\section{KESIMPULAN}

Model Bangkitan pergerakan dari Perumahan de Green Grande Y1=6,068+1,239 X4 +1,435 X5 + 0,855 X7+1,166 X8. Model Bangkitan pergerakan dari Jingga Residence Y2 = 2,554 + 1,143 X3 + 1,041 X4 + 1,011 X5 +1,256 X6 + 1,2045 X7. Model Bangkitan pergerakan dari Perumahan Pesona Ciwastra Permai $\mathrm{Y} 3=7,540+2,874$ X5 + 1,696 X6 + 0,552 X8. Model Bangkitan pergerakan dari Buana Ciwastra Y4 = $5,840+1,143 \mathrm{X} 3+2,108$ X5 + 1,3295 X6. Berkembangnya suatu kawasan seharusnya berimbang dengan perencanaan jaringan jalan. Hasil penelitian ini dapat dijadikan bahan pertimbangan untuk perencanaan pengembangan wilayah dan transportasi di sekitar ruas Jalan Ciwastra. 


\section{DAFTAR PUSTAKA}

Akbardin, J. 2005 Analisis Pengaruh Bangkitan Pergerakan Permukiman terhadap Kinerja Ruas Jalan Ciwastra Kota Bandung, Jurnal Tatal UNISFAT

Akbardin, J. (2013) Variable Relationships Estimation Of Cargo Transportation Network System To The Number Of Internal Regional Cargo Mode (Case Study Of Road Network System in Central Java Province), Jurnal Magister Teknik Sipil UMS

Akbardin, J., Andri Eka Putra 2016 Analisa BOK (Biaya Operasi Kendaraan) Shuttle Service Rute Bandung-Jakarta Selatan, Jurnal Media Teknik Sipil UMM

Akbardin, J., Khoiriyah K, Supratman O, Samsudin A, Wibowo, FC, (2017) The Indonesian Vocational Students' Understanding on Educational Activities Center toward characteristic of user Location Accesbilities, Turkish online Journal of Educational Technology 1, 426-431

Akbardin, J., et.al (2018) The Influence of Freight Generation Production Characteristics of the InternalRegional Zone Commodities on Sustainable Freight Transportation Highway Network System. Matec Web Conference

Akbardin, J., et.al (2018) The Influence of Highway Transportation Infrastructure Condition Toward Commodity Production Generation for the Resilience Needs at Regional Internal Zone. E3S Web Conference

Akbardin, J., et.al (2018) The distribution system simulation model of each zone freight transportation movement based on unlimited the gravity model algorithm. IEEE explore

Akbardin, J (2019) Evaluation Of Parking Area Sport Activities Base On Land Use Needs Education Activities System, Journal of Architectural Research and Education Vo. (1) No.1

Badan Pusat Statistik (2013). Modul Diklat Fungsional Statistisi Tingkat Ahli: Analisis Regresi dan Korelasi. Jakarta: BPS.

BAPPEDA. (2010). Rencana Tata Ruang Wilayah Kota Bandung Tahun 2011-2031. Bandung: Pemerintah Kota Bandung.

Black, J. A. (1981). Urban Transport Planning : Theory and Practice. London : Croom Helm.

Khisty, C. J., dan Lall, B. K. (2003). Dasar-dasar Rekayasa Transportasi Jilid 1 Edisi Ketiga. Jakarta: Penerbit Erlangga.

Morlok, Edward K. (1991). Pengantar Teknik dan Perencanaan Transportasi. Jakarta: Penerbit Erlangga.

Sugiyono. (2011). Metode Penelitian Kuantitatif, Kualitatif, dan R\&D. Bandung: Alfabeta.

Syaiful, Lutfi Akbar, 2015. Analisis Pengaruh Kecepatan Lalu lintas Terhadap Kebisingan yang Ditimbulkan Kendaraan Bermotor. Jurnal Rekayasa Sipil ASTONJADRO, 4 (1), pp.13-19.

Syaiful, 2015. Tingkat Resistensi Polusi Suara di Depan RSIA Sentosa Bogor. Jurnal Rekayasa Sipil ASTONJADRO, 4 (2), pp.57-61.

Tamin, O.Z. (1997). Perencanaan dan Pemodelan Transportasi Edisi Kesatu. Bandung: Penerbit ITB. 